\title{
Imbricações entre aprendizagem de Física e masculinidades numa educação em crise
}

\author{
Josimeire Meneses Julio \\ Universidade Federal de São Carlos, Brasil \\ Arnaldo de Moura Vaz \\ Universidade Federal de Minas Gerais, Brasil
}

\begin{abstract}
Resumo
No contexto da chamada crise na educação masculina, procura-se caracterizar aspectos latentes de masculinidades que trazem implicações para a aprendizagem individual e coletiva no ensino secundário. A metodologia teve inspiração etnográfica: aulas de Física de uma turma de primeira série foram acompanhadas ao longo de um ano. Foi realizada microanálise de uma unidade temática, com foco nas interações predominantes entre rapazes. Apresentam-se três aulas em detalhe gravadas em áudio e em vídeo. Algumas manifestações de masculinidade predominaram entre rapazes em situações desafiadoras, de competição, e outras, em que regras devem ser observadas. Os resultados indicam em que circunstâncias há possibilidade dessas manifestações das masculinidades comprometerem o desenvolvimento das atividades em sala de aula e o funcionamento de grupos de aprendizagem.
\end{abstract}

Palavras-chave

Representações de masculinidade; Ensino de Física; Atividade investigativa

\section{Introdução}

O debate sobre a crise da educação masculina ganhou força no início do século XXI, tendo como um dos motes o fato de que, desde os anos 1990, 
meninos e rapazes figuravam progressivamente em desvantagem, nas estatísticas educacionais, em relação às meninas e moças. Um fenômeno que, associado a outros, se tornou motivo de inquietação em diferentes contextos econômicos e sociais, tanto em países desenvolvidos, quanto em países em desenvolvimento. Por exemplo, na Grã-Bretanha, Estados Unidos e Austrália teme-se que haja uma relação entre fracasso escolar masculino e fatores sociais mais críticos como violência, desemprego, drogas e monoparentalidade (Carvalho, 2003, 2004; Giddens, 2005; Louro, 1992; Martino \& Meyenn, 2001). A constatação mais preocupante é a de que os rapazes ora são protagonistas de violência - como autores ou vítimas -, ora são levados à evasão, sobretudo do ensino secundário.

Nesse debate, as falhas observadas na educação escolar masculina chamaram a atenção para os modelos de masculinidade que permeiam o universo dos rapazes (Carvalho, 2001; Connell, 2000; Martino \& Berril, 2003; Martino \& Meyenn, 2001). Connell (1995) é um autor que se antecede a esse debate; ele define masculinidade a partir de uma abordagem relacional das práticas e configurações sociais entre grupos de homens e mulheres e dentro desses grupos. Essa abordagem engloba tanto a dominação dos homens sobre as mulheres, quanto disputas entre diferentes grupos de homens para obter posição e controle, articular e rearticular a relação entre masculinidade e poder.

Com reflexões como essas sobre o tema, percebe-se que, além de múltiplas, as masculinidades são mutáveis e definem-se de maneiras diferentes em grupos diferentes. A construção e internalização das masculinidades é um processo complexo que começa na infância, através da família, da sociedade, da mídia. As estórias e brincadeiras infantis tipicamente masculinas são determinantes nesse processo, pois despertam nos meninos a necessidade de emancipação através da descoberta, investigação, exploração e dominação do mundo (Blakemore \& Centers, 2005; Statham, 1986, apud Giddens, 2005).

A constituição das masculinidades é um processo que se dá em função de fatores complexos da organização social, muitos dos quais diretamente imbricados na escola. Para Weaver-Hightower (2003), esses fatores evidenciam privilégios masculinos e colocam meninos e rapazes no topo das posições de desempenho, especialmente em disciplinas escolares de alto 
prestígio como ciências naturais, ciência da computação e matemática avançada. Uma grande evidência desta distinção é que, "no ensino secundário, as mulheres tendem a ficar invisíveis para a maioria dos livros de ciências e de matemática, eternizando a visão de que essas são disciplinas masculinas" (Giddens, 2005: 415, grifo do autor). Isso porque o conhecimento científico - tido como hegemônico na cultura ocidental - não raro é associado a características masculinas, na visão dominante da divisão sexual (Bourdieu, 1995; Chassot, 2003; Donini, 2001).

Há que se destacar que rotinas e normas de trabalho escolar passivas e recolhidas incomodam muitos rapazes, seja por não atenderem seus interesses, seja por mobilizarem disposições e atitudes que eles consideram femininas (Giddens, 2005; Rocha \& Ferreira, 2002). Isto influencia a maneira como os rapazes percebem e se dedicam à escola. Contudo, cada área ou disciplina escolar exerce seu próprio apelo. A Física está entre as disciplinas de alto prestígio, pois é icônica de um ideal de racionalidade muito valorizado na cultura ocidental. Como ciência, ela ainda hoje reproduz padrões de masculinidade nos quais se fundamentou por longos anos (Chassot, 2003; Donini, 2001).

O objetivo deste trabalho é caracterizar aspectos das masculinidades latentes dos rapazes imbricados à Física e que trazem implicações, tanto para sua aprendizagem individual, quanto para o aproveitamento coletivo de alunos e alunas do ensino secundário. Toma-se para análise uma unidade temática de Física. Usando recursos da etnografia, destaca-se o que facilita a ação ou promove uma atitude ativa dos rapazes no que se refere à própria Física e às tarefas escolares.

O quadro dos padrões de masculinidade de Connell (1995) inspirou a análise das interações que ocorreram em sala de aula, através da articulação com pesquisas semelhantes (Brito, 2006; Cruz \& Carvalho, 2006; Souza, 2006). Algumas atitudes ativas que ocorreram em torno de certas manifestações de masculinidade predominaram entre os rapazes em situações desafiadoras, de competição, e outras, em que regras devem ser observadas. 


\section{O quadro das masculinidades}

O trabalho bem sucedido em torno das teorias feministas através dos anos 1970, 1980 e 1990, investigando como o gênero influenciava a vida das mulheres, abriu espaço para o questionamento sobre os papéis masculinos na sociedade ocidental (Connell, 2000). A partir daí, diversas questões sociais mostraram-se passíveis de exame e intervenção. Entre essas questões estavam relações familiares, sociais, econômicas e aspectos físicos da vida masculina associados ao trabalho, distúrbios emocionais, saúde, divórcio e disputas de custódia, imagem do corpo e violência, entre muitas outras (Weaver-Hightower, 2003). As críticas a esses aspectos da organização social constituíram a literatura sobre o público masculino.

O conceito de masculinidade é definido por Connell (1995) como essencialmente relacional. $\mathrm{O}$ uso do termo assume que a conduta de uma pessoa resulta daquilo que ela é, levando em conta as diferenças individuais e a ação pessoal. Esse conceito é apresentado no sentido da cultura moderna européia/americana, que trata os tipos de caracteres de homens e mulheres como caracteres polarizados. Desse modo, a masculinidade surge, em princípio, do contraste com a feminilidade. A masculinidade "é ao mesmo tempo a posição nas relações de gênero, as práticas pelas quais homens e mulheres se comprometem com essa posição de gênero, e os efeitos dessas práticas na experiência física, na personalidade e na cultura" (Connell, 1995).

Segundo Connell (1995), há um padrão hegemônico de masculinidade em cada sociedade que identifica uma política de gênero condutora de relações de aliança, de dominação e subordinação entre as diversas masculinidades. $\mathrm{O}$ autor destaca que, no Ocidente, atualmente, imperam os mesmos padrões de hegemonia. Haenfler (2004) defende que a masculinidade hegemônica ocidental legitima e valoriza principalmente a competição, a hierarquia, o individualismo, as proezas sexuais, a força corporal, a racionalidade, a distância emocional, a dominação e a coragem de se arriscar.

Ainda segundo Connell (1995), na interação entre grupos de homens surgem dois outros padrões de masculinidade: subordinação e cumplicidade. A subordinação é a posição inferiorizada e estigmatizada de grupos de homens que se encontram fora do círculo de legitimação da masculinidade 
hegemônica. Os homossexuais são o caso mais representativo, mas grupos que tenham semelhança simbólica com o feminino também se inserem nesses grupos, sendo taxados por um vocabulário abusivo - "nerd", filhinho da mamãe, covarde, "mulherzinha", entre outros. O padrão de cumplicidade garante aos homens em geral os privilégios adquiridos pelo patriarcado. A cumplicidade permite a conexão com o projeto hegemônico vigente, mesmo que as normas hegemônicas não sejam adotadas rigorosamente.

Para Connell (1995), a masculinidade interage com as estruturas sociais de raça e classe segundo um padrão de marginalização entre grupos dominantes e dominados. A marginalização sempre envolve uma expectativa de "autorização" do grupo dominante para que um integrante do grupo subordinado possa se tornar um legítimo representante da masculinidade hegemônica. Assim, personalidades em destaque como atores, atletas e políticos oriundos de grupos étnicos e econômicos socialmente desfavorecidos - como é o caso de índios, negros, pobres -, podem ser exemplos do modelo hegemônico vigente.

O conceito de masculinidade hegemônica tem sido aplicado em estudos educacionais para compreender a dinâmica das salas de aula, inclusive padrões de resistência e a prática do "bullying" entre os meninos e rapazes (Connell \& Messerschmidt, 2005; Martino \& Berril, 2003; Martino \& Meyenn, 2001; Statham, 1986, apud Giddens, 2005; Swain, 2006).

Swain (2006) toma de empréstimo a teoria de masculinidade de Connell para propor outras formas de masculinidade. $O$ estudo identifica, no contexto escolar, masculinidades personalizadas, que acrescentam novas denominações nas teorias de masculinidade ou são novas maneiras de descrever as condutas nesse espaço. Essas formas personalizadas de masculinidade não são hegemônicas, pois não fazem parte de uma agenda cultural onde outros meninos e rapazes queiram assinar. Elas são mais reservadas e não despertam desejo ou necessidade de desafiar ou constranger outras formas (Swain, 2006). Dessa maneira, se revelam formas alternativas de masculinidades que não desafiam ou resistem às prescrições hegemônicas.

Há poucos estudos que recorrem ao conceito de masculinidade para investigar as relações que se estabelecem no contexto escolar (Brito, 2006; Cruz \& Carvalho, 2006; Souza, 2006). Esses estudos procuram compreender 
os significados das interações de gênero, seu papel na construção das identidades de meninos e meninas, bem como as relações de poder que se estabelecem a partir das masculinidades e feminilidades construídas. Eles deixam de lado visões estereotipadas das interações de alunos e alunas, na sala de aula, em favor de observações mais focadas. Entretanto, são realizados no contexto da educação infantil, onde se estabelecem relações sem influência de conteúdos específicos, como no caso deste trabalho.

Brito (2006) revela que trajetórias escolares bem sucedidas não correspondem necessariamente aos estereótipos da aluna quieta e passiva e do aluno perturbador. Cruz \& Carvalho (2006) verificaram que, brincando ou brigando juntos, meninos e meninas estabeleciam jogos de gênero que tanto reforçavam a oposição entre os significados de masculinidades e feminilidades quanto, ao contrário, atenuavam-lhes as fronteiras. Entretanto, "como parte da sociedade, a escola se constitui num contexto múltiplo e contraditório para as ações individuais, mas nela parecem predominar significados de gênero associados a bi-polaridade, ao antagonismo e à hierarquização" (Cruz \& Carvalho, 2006). Para Souza (2006), há uma fragmentação no grupo de meninos marcada por questões como desempenho escolar e masculinidade. Tanto meninas quanto meninos apresentaram uma diversidade de posturas, comportamentos, preferência e atitudes que impedem a identificação de dois grupos homogêneos.

Neste estudo recorre-se ao conceito de masculinidades de Connell (1995) para investigar as masculinidades estimuladas em uma seqüência de aulas de Física e o modo como essas masculinidades convivem nesse contexto.

\section{Desenho metodológico}

Cuidados éticos para a proteção dos estudantes foram aprovados em Comitê de Ética e Pesquisa vinculado ao sistema da Comissão Nacional de Ética em Pesquisa do Brasil. Alunos, alunas e seus responsáveis autorizaram a participação voluntária no estudo por meio de assinatura de termo de consentimento livre e esclarecido. Os nomes citados são fictícios, não se assemelham aos nomes de qualquer participante.

O delineamento metodológico do estudo se inspirou na etnografia. Taft 
(1999) considera que um pesquisador que investiga a subcultura de uma escola em sua própria sociedade pode ser comparado a um estranho que inicia um estudo antropológico em uma sociedade tradicional. A aculturação naquele meio transforma o observador em um amigo que conhece a "linguagem silenciosa" do grupo e a íntima comunicação entre seus membros.

O grupo investigado é uma turma de primeiro ano do ensino secundário, observada ao longo de um ano em todas as aulas de Física. A íntima comunicação entre seus membros ocorre em torno de diferentes variáveis - entre elas: a relação dos alunos com o professor, com a atividade, com os colegas de outros grupos e com a Física. Aqui, a masculinidade é a "linguagem silenciosa" desconhecida, que se articula com todas essas variáveis em diferentes dimensões. $\mathrm{O}$ acompanhamento das aulas permitiu que se traçasse o perfil de cada estudante. A partir daí, suas interações foram analisadas durante um episódio, bem recortado no tempo: uma atividade com início, meio e fim, gravada em áudio e em vídeo ao longo de duas semanas.

O processo de análise dos dados - inspirado no trabalho de um etnógrafo - deu-se com um delineamento de pesquisa do tipo descritiva, com ênfase em descrições detalhadas de aspectos holísticos do funcionamento dos grupos a partir da observação das aulas. Os resultados obtidos foram descrições analíticas que buscaram retratar o contexto e as interações dos participantes observados. Estas descrições privilegiavam o reconhecimento e a classificação de dimensões complementares da ação recíproca dos indivíduos do grupo com cada situação de aprendizagem.

As descrições deram aporte a nova análise dos grupos, através dos episódios e seqüências de ação, tomando como referência: (a) a relação dos indivíduos entre si; (b) a relação do grupo com a atividade; (c) a relação do grupo com a Física; e (d) a relação do grupo com os outros elementos do contexto - como o professor e os outros grupos.

Um outro nível de análise evidenciou quatro instâncias do funcionamento dos grupos. A primeira enfatiza as relações de poder e a articulação entre os componentes do grupo enquanto organizam seu trabalho. A segunda remete ao modo como o grupo lida com aspectos próprios da atividade, entre eles necessidade de tomadas de decisão, desenvolvimento da autonomia, planejamento da solução do problema. A terceira denota a relação do grupo com o objeto de conhecimento da Física, com a objetividade, 
com a investigação do mundo. A quarta representa o posicionamento do grupo perante os outros grupos e o professor.

As informações reveladas levaram à: (i) identificação das características comuns aos rapazes envolvidos na situação de aprendizagem; (ii) caracterização descritiva dos aspectos facilitadores da ação dos rapazes; (iii) caracterização descritiva dos aspectos inibidores da ação dos rapazes; (iv) análise cruzada dos resultados obtidos nas etapas "ii" e "iii" para os diversos tipos de situações de aprendizagem segundo dois pontos de vista, o da Física e o da atividade. As descrições analíticas produzidas se prestaram ao exame das ações dos rapazes como ações masculinas e de sua manifestação em relação à Física e à atividade. Tais ações foram analisadas no quadro teórico das representações de masculinidade de Connell (1995), procurando-se identificar entre elas nuances de um padrão hegemônico de masculinidade.

\section{A turma acompanhada}

Nesta turma, perfis individuais se sobressaem, há alunos e alunas que tendem a trabalhar individualmente. Eles mantêm-se centrados em fenômenos da Física, enquanto elas fazem mais perguntas que envolvem o esclarecimento ou a compreensão das tarefas de sala de aula e se manifestam pouco em discussões com toda a turma. As moças tendem a se manter caladas e atentas, durante as exposições do professor; quando desejam se manifestar, elas levantam o braço e esperam sua vez de falar. Os rapazes propendem a fazer algum comentário ou brincadeira entre si sempre que o professor aguarda manifestações individuais na turma ou faz uma pausa mais prolongada. Quando são estimulados por algum desafio, problema ou questão a ser resolvida, tentam monopolizar as discussões coletivas.

O professor estimula a participação de toda a classe nas discussões coletivas e, freqüentemente, convoca alunos e alunas mais introvertidos a falar. Rapazes e moças reagem de maneiras diferentes a estes apelos. Elas tendem a ficar caladas, mostrando-se tímidas e nervosas; eles participam mesmo quando estão tímidos. Nessas discussões, o modo de falar das moças é mais calmo e suave, entretanto demonstram mais ansiedade no tom de voz. Berta é uma exceção: ela normalmente enfrenta os colegas e, sempre que 
quer ser ouvida, exige atenção - tanto dos colegas como do professor. Os rapazes normalmente atropelam as falas dos colegas, e têm muitas perguntas; procuram se expressar com segurança, como quem quer convencer o outro de seus argumentos.

Alunos e alunas enquadram-se em quatro perfis. No primeiro enquadram-se rapazes que tendem a dominar o espaço da sala de aula, como é o caso de Willian, Roger, César e Max: sempre que têm oportunidade, levantam-se, andam pela sala de aula, brincam e dispersam a atenção dos outros colegas. No segundo, a tendência é dominar as discussões sobre Física: Leonardo, Jean, George, José, James, César, Berta, Carmen, Matilde, Alessandro. O terceiro perfil ajusta-se aos que, quando interpelados pelo professor, dão boas contribuições para a discussão: Roger, Charles, Mário, Gabriel. O quarto perfil mantém-se "invisível" nas aulas: Lélio, Valentina, Michael, Belita, Nicolau, Caroline, Amélia, Tales, Irene (que tem postura ativa em seu grupo).

\section{A unidade temática instrumento da microanálise}

Um conjunto de aulas compõe a unidade temática à qual se recorreu para destacar características identificadas nas interações dos alunos durante as aulas, ao longo de um ano de observação. Esta unidade temática, denominada "atividade das estrelas variáveis", ocupa seis aulas de cinqüenta minutos. Nesta atividade, as tarefas permitem que os alunos vivenciem o processo de descoberta, a busca por evidências que comprovem previsões ou descartem a ocorrência de um fenômeno, a disciplina para realizar medidas, a negociação de expectativas e a organização de um plano de trabalho. O propósito é que os alunos simulem o trabalho de uma comunidade científica, inclusive através de discussões e comunicação entre "pares".

Dezoito fotografias são entregues a grupos de três ou quatro alunos e alunas. Nelas, há uma legenda que identifica uma região do céu - a mesma em todas fotografias - e a data da foto. Alunos e alunas devem observar as fotografias, que foram previamente embaralhadas, e descobrir se há algum fenômeno que valha a pena ser estudado. Para identificar o fenómeno, alunos e alunas devem estabelecer um plano de trabalho, dividir tarefas e negociar expectativas com seus colegas de grupo. Eram oito grupos, organizados pelo 
professor no primeiro dia de aula, fixos ao longo do ano: Grupo A - Alessandro, Amélia e César; Grupo B - Charles, Gabriel e George; Grupo C - Belita, James e Jean; Grupo D - Berta, Carmen e Caroline; Grupo E -Irene, José e Julios; Grupo F - Lélio, Leonardo e Matilde; Grupo G - Mário, Max, Michael e Valentina; Grupo H - Nicolau, Roger e Tales.

A atividade é "aberta" a diferentes encaminhamentos; desse modo, suscita análises, negociações e distribuição de funções. Ocasionalmente, o professor convoca todos para plenária: com os depoimentos dos grupos, novas facetas da atividade surgem e novos desafios ou dificuldades precisam ser superados. Além disso, as plenárias permitem que todos partam para novas tarefas sempre do mesmo nível, com as mesmas informações que os outros.

As seis aulas desta seqüência de ensino foram analisadas da mesma maneira. Apresentam-se a seguir descrições aprofundadas e análise de três dessas aulas. Essas três primeiras aulas são descritas aqui, pois nelas identificaram-se relações que envolvem um padrão hegemônico de masculinidade. As demais aulas da seqüência de ensino ocorreram em torno de tarefas mais específicas determinadas pelo professor, como realização de medidas, construção de tabelas e gráficos e interpretação do fenômeno. Durante as três ultimas aulas da seqüência de ensino, houve uma certa homogeneidade nas relações que se estabeleceram entre alunas e alunos, ocasionando um apagamento do padrão hegemônico de masculinidade.

\section{Primeira aula}

O professor começa a aula anunciando a alunos e alunas o prazer que sentirão desvendando mistérios ou fazendo descobertas. Ele compara a atividade a um jogo, onde, para começar, dados coletados por cientistas deverão ser analisados, para avaliar se ali há algum fenômeno que vale a pena ser estudado, e distribui os pacotes com as fotografias. Nos grupos, os alunos abrem os pacotes e começam a analisar as fotografias, para tentar descobrir do que se trata - como se segue abaixo.

Grupo B: George, Gabriel e Charles percebem as datas e colocam as fotografias em ordem cronológica. George alinha todas as folhas umas sobre as outras e as passa rapidamente ,sem perceber nada. Gabriel conta e divide 
as fotografias em quantidades iguais entre eles, para que cada um fique com uma seqüência. Enquanto cada um examina as fotografias a seu modo, levantam possibilidade de haver dois tipos de movimento ocorrendo. O grupo trabalha em harmonia, buscando evidências de um fenômeno. Logo em seguida, o professor convoca a turma para a primeira plenária.

Grupo D: Berta começa a atividade comentando com Caroline sobre buracos negros. Ao receber as fotografias, Caroline mostra a Carmen e Berta que se trata de uma região do céu. Percebem que uma estrela se parece com o "Mickey". Dividem as folhas entre si e as colocam em ordem cronológica. Berta consulta o professor sobre como as fotografias foram tiradas, ele diz que não pode revelar. Caroline lembra que a região do céu é a mesma e que a câmera pode ter mudado de posição. Berta quer descobrir como as fotografias foram tiradas. Caroline ensina que as colegas devem tomar "Mickey" como referência e avalia que seja a mesma região do céu. Berta constata que as posições das estrelas em relação ao "Mickey" são "exatamente iguais" e que não se movem umas em relação às outras. Quando se empolgam durante a comparação, o professor convoca os grupos para a plenária.

Grupo H: Tales, Roger e Nicolau são um grupo mais disperso que os outros; mesmo assim, dedicam-se à realização desta atividade. Nicolau pede que os colegas comecem a trabalhar. Roger tenta distrair Tales e Nicolau, mas Nicolau diz que precisam descobrir o fenômeno. Eles percebem um aparente movimento das estrelas e Nicolau tenta explicar por que esse movimento ocorre. Nicolau diz que encontraram um fenômeno e se alvoroçam para chamar o professor, que não os ouve.

Após 15 minutos de trabalho nos grupos, o professor faz uma "chamada geral" e solicita que os representantes dos grupos digam "o que foi feito na busca pelo fenômeno?". Cada grupo terá sua vez de falar; devem falar em ordem, criticando ou acrescentando informações nas observações dos colegas, mas sem repetir o que os outros já disseram.

José, do grupo E, diz que colocaram as folhas contra a luz para ver se havia diferenças entre as fotografias. Berta, do grupo $D$, conta que colocaram as fotografias na ordem das datas e então as compararam. Leonardo, do grupo $F$, destaca que colocaram em ordem e foram comparando uma foto com outra, observando a diferença entre a posição das estrelas, mas "sem nenhuma seqüência"; então, fizeram a superposição de fotografias. 
Alessandro, do Grupo A, faz referência ao fato de que, em algumas datas, há uma rotação para a esquerda. O professor chama a atenção dos alunos para o fato de que ainda não é o momento de falar sobre qual o fenômeno que vale a pena estudar. Em seguida, pergunta se alguém pretende comentar algo que ainda não tenha sido dito. James pede a palavra e menciona que o que está sendo observado se repete ao longo do tempo. $O$ professor diz que ele não acrescentou novidades sobre a busca e ressalta a dificuldade de todos em entender a pergunta sobre o que fizeram; diz que poderiam ter olhado para o que os outros grupos faziam. Numa síntese, destaca contribuições em plenária que foram pertinentes: colocar as fotografias em ordem; superpor fotografias; tomar uma estrela como referência; e estabelecer um modo de comparação entre estrelas. Ele enfatiza o "Mickey" como uma importante referência espacial e as datas como uma referência temporal.

Uma nova fase do debate em plenária é estabelecida: os alunos devem dizer agora que possíveis fenômenos foram identificados. Os grupos devem responder às seguintes questões: Há algum fenômeno que valha a pena investigar? Qual fenômeno?

Alguns alunos ficam mais atentos, agitam-se nos grupos, verificam o que ocorre nas fotografias, levantam os braços em seguida, na intenção de comunicar o que observaram. César diz imediatamente:

- César: Rotação!

José inicia uma frase e, prontamente, levanta o braço. Berta também levanta o braço, em silêncio. O professor dá voz a um grupo que ainda não havia falado. José desiste. Berta mantém o braço esticado, esperando sua vez. Nos grupos $B, C, D$ e $E$, alunos consultam as fotografias, enquanto $O$ grupo faz sua exposição. Logo em seguida, Berta tem sua vez; ela avisa que tem uma referência ao fenômeno e uma dúvida:

- Berta: Por quê...

- Professor: Qual o fenômeno você acha que... (reforça o professor)

Berta relata que observou que a distância entre as estrelas não muda. Nesse momento, George tenta interrompê-la e dirige-se ao professor, atropelando a fala da colega:

- George: Mas eu acho... 
O professor, atento à aluna, faz um gesto para que George aguarde sua vez e deixe a colega concluir seu raciocínio. Berta diz que a posição das estrelas, umas em relação às outras, não muda (simula um giro, com as mãos sobre as fotografias, para sinalizar que todas as estrelas se moveram juntas na mesma direção). Na seqüência, ela começa a expor sua dúvida e argumenta que, se as fotografias não foram tiradas na mesma hora, não há como saber se é porque a Terra gira (expressa essa ideia girando as mãos e o corpo). O professor a interrompe, diz que ela já fez a tarefa e reafirma:

- Professor: A tarefa é listar agora os fenômenos possíveis de serem investigados.

Outros grupos não se manifestam e George tem sua vez de falar. Ele segura em suas mãos as fotografias superpostas. Diz que olhando daquele modo, mirando o "Mickey", viu que algumas estrelas se "movem mais, outras voltam para uma direção completamente diferente", e afirma enfaticamente:

- George: Então eu acho que tem movimento das estrelas!

Gabriel emenda a fala do colega de grupo e diz:

- Gabriel: É! No caso da constelação do "Mickey", ela gira sempre no mesmo lugar sempre ligada no mesmo ponto inicial. $A$ "orelhinha" sempre vai rodar no mesmo lugar, (desenha uma circunferência no ar, referindo-se ao movimento das orelhas do "Mickey").

O professor chama a atenção para a contradição existente entre as afirmações dos dois colegas e as de Berta. Ela havia acabado de dizer que não existe movimento das estrelas. Alessandro reforça:

- Alessandro: As estrelas estão paradas, o que se movimenta é a Terra.

Novamente o professor chama a atenção para as perguntas: "O que vale a pena estudar?" e "Qual o fenômeno?". Aponta as principais dificuldades dos alunos em dizer o que fizeram na busca pelo fenômeno, e solicita enfaticamente que os alunos respondam "Qual o fenômeno?", e não "Por que ele ocorre?". César consulta as fotografias, chama o professor, levanta $o$ braço e diz:

- César: Qual o fenômeno que foi observado? Foi o movimento da Terra, que eu acho, e das estrelas. 
- Professor: Você observou o fenômeno da Terra? Você observou o movimento da Terra?

Berta levanta o braço imediatamente.

- César: Observei, no sentido fotográfico (fazendo movimento de rotação com as mãos).

O professor volta-se para os outros grupos e pergunta se observaram o movimento da Terra e se há evidências nas fotografias. Obtém respostas afirmativas de alguns alunos. Ele percebe que Berta continua com o braço levantado, aguardando sua vez. Faz um sinal para que ela aguarde mais um pouco e dá a palavra a Gabriel, que está acenando. Gabriel sugere que estão falando em rotação das estrelas tomando por base a teoria do movimento de rotação da Terra, e não observando diretamente. O professor pergunta se é possível observar movimento das estrelas nas fotografias. Os alunos dizem que sim. Ele complementa:

- Professor: Em "relação ao Mickey?"

Berta e Gabriel dizem que não. O professor pede evidências do que os grupos observaram e, finalmente, volta-se para Berta, que continuava em silêncio com o braço levantado:

- Professor: O quê que vocês observaram?

- Berta: A gente observou o movimento das estrelas em relação à margem do papel... (fazendo movimentos circulares com as mãos, sobre as fotografias).

- Professor: Em relação à margem do papel!!! (volta-se para a turma, agitando o dedo em riste).

- Berta: Em compensação, depois a gente observou que não tem movimento das estrelas em relação a elas.

O professor pergunta se o "movimento da Terra" pode ser observado nas fotografias. Gabriel diz que é só uma teoria. O professor destaca os enganos dos alunos com relação à observação sobre o movimento das estrelas e estabelece uma nova competição em grupo, já nos cinco minutos finais da aula, para que tentem novamente identificar um fenômeno.

Grupo B: Gabriel explica aos colegas que o "Mickey" gira sempre em torno do mesmo ponto, sempre na mesma posição, e que devem tomar as 
"orelhinhas" como referência para observar as estrelas próximas ao "Mickey" em cada uma das fotografias. Neste intervalo, Berta grita que uma estrela diminui de tamanho; o grupo está tão compenetrado que não percebe. George superpõe duas fotografias, levanta-as um pouco acima da cabeça e observaas contra a luz. Charles sugere a George que superponha as orelhas do "Mickey" para ver se as outras estrelas se movem. Gabriel interpela Charles e diz que as estrelas giram em relação à margem do papel, não umas em relação às outras. Ao mesmo tempo, George chama Gabriel, aponta para uma região das fotografias e solicita que ele confirme se há uma estrela que diminui de tamanho, Gabriel confirma a mudança de tamanho. George, inquieto, levanta o braço e chama o professor, que está atendendo a um outro grupo e não vê. Gabriel solta um grito de satisfação e faz em cada mão um " $V$ " (expressava vitória por haver descoberto algo), com os dedos, acenando rapidamente para a câmera. O professor vai à frente da sala encerrar a aula e não atende ao chamado de George, que agita os dois braços.

Grupo D: Logo que começam a examinar as fotografias, Berta empinase sobre a carteira, de repente, olha para frente, agita-se e exclama em voz alta:

- Berta: Uma estrela diminuiu de tamanho! Como assim?!

Carmen pega algumas fotografias que estão com Berta e as examina. Berta volta a debruçar-se cuidadosamente sobre as fotografias. Ela levantase, debruça-se sobre a carteira de Caroline, mostra a estrela que diminuiu e chama o professor, que está do outro lado da sala, atendendo a um grupo, e não a ouve. Ela chama-o mais uma vez, levanta o braço e exclama novamente, sem que ele a perceba:

- Berta: Ô professor! Eu vi uma estrela que diminui de tamanho!

Nesse momento, Matilde volta-se para ela, que acaba de sentar-se ainda agitada, e as duas conferem a posição da estrela nas fotografias. Em seguida, Matilde alerta Berta:

- Matilde: Você não podia contar, hein!

Berta chama de novo o professor, esticando mais ainda o braço, e volta a conferir as fotografias. Lamenta que o professor esteja ocupado e não a veja. Em seguida, o professor encerra a aula, sem que Berta tenha a chance de contar sua descoberta. 
Grupo H: O grupo esboça a tentativa de identificar o fenômeno, mas logo se dispersa e desiste da tarefa.

A aula foi encerrada sem que nenhum dos grupos tivesse a chance de revelar a descoberta ao professor ou ao coletivo da turma. O professor apenas anunciou que a investigação teria prosseguimento na aula seguinte. Esses cinco minutos finais da primeira aula seriam determinantes para o que iria ocorrer no início da segunda aula.

\section{Análise da primeira aula}

O tópico da aula não é tratado nos níveis escolares precedentes. Portanto, os grupos iniciaram a atividade em um mesmo nível: nenhum deles poderia contar com algum privilégio em relação aos outros, sobre o fenômeno. Observa-se que houve entre eles predisposições para o desafio de fazer uma descoberta e para a competição, que se manifestaram de diferentes maneiras entre os rapazes, mas que não foram identificadas entre as moças.

Há paralelo entre o observado e o padrão hegemônico de masculinidade proposto por Connell (1995) e reforçado por Haenfler (2004). Observamos, na primeira parte da aula, que alguns rapazes se mobilizaram onde a atividade lhes deu a oportunidade de competir, usar sua força ou assumir dominação de algum tipo. Quando isso ocorreu, eles não estabeleceram uma relação de colaboração dentro dos grupos.

Nos grupos A e C, os rapazes entraram em conflito ao disputarem a mesma posição dentro do grupo e ao tentarem se impor pela força; a divisão de tarefas para enfrentar o desafio de fazer uma descoberta foi deixada de lado e eles não avançaram na investigação. No grupo A, César assumiu de maneira impositiva a organização do plano de trabalho, mas Alessandro se opôs. Alessandro sabotou o comando de César envolvendo-se pouco com as tarefas, comprometendo a organização e análise das fotografias. No grupo $\mathrm{C}$, James e Jean duelaram pelo comando da investigação, criaram um impasse que impediu o estabelecimento de um plano de trabalho e a divisão de tarefas; perceberam apenas que, após algum tempo, as fotografias se repetiam.

No grupo $\mathrm{H}$, outras cores do padrão hegemônico de masculinidade colocam-se em destaque, em torno da relação de Roger com Tales e Nicolau, e denotam posicionamento hierárquico, individualismo e racionalidade 
dominadora. Eles não disputaram o comando do grupo. Por um lado, Roger impôs seu comando, contestando as ideias dos colegas sem dar a eles a oportunidade de argumentá-las; analisou as fotografias, apresentou sua interpretação sem discutir com eles e não permitiu que seguissem em frente. Por outro lado, Nicolau e Tales concederam-Ihe o comando e não contestaram seu posicionamento. A autoridade concedida a Roger ocorria em torno de seu prestígio intelectual, evidenciado pelo domínio que demonstrava em relação ao conhecimento científico. Tratava-se de uma estratégia racional do grupo para permanecer na frente dos outros grupos, na investigação. Uma evidência disso é o fato de que a explicação elaborada por Roger, ao analisar o fenômeno, foi acatada com entusiasmo por Nicolau, uma vez que poderiam estar em vantagem em relação aos outros grupos. Isso reforçava a atitude prepotente e individualista de Roger, que preferiu desconsiderar as observações feitas por Tales e Nicolau inibindo-as, apresentando explicações que levaram em conta apenas seu ponto de vista e suposto conhecimento prévio.

Nos grupos B, D, E e F, outras relações mais positivas se estabeleceram: alunos e alunas exploraram as fotografias de várias formas possíveis conseguindo manter-se na busca pelo fenômeno, confrontando evidências entre si em uma dinâmica colaborativa.

O modelo hegemônico de competição, força, dominação e coragem de se arriscar se fez presente também durante a plenária, quando os grupos deveriam dizer "Que fenômeno vale a pena estudar?". Os rapazes mostraramse aguerridos, tanto na maneira de chamar a atenção do professor, quanto na forma de se expressarem. A tendência entre todos aqueles que se propuseram a participar era irromper a discussão antes de fazer algum sinal ou aguardar sua vez, enquanto as moças aguardavam em silêncio com o braço levantado. Essas estratégias dos rapazes remetem a condutas que, quando naturalizadas pela escola, inibem outras formas de participação no espaço coletivo da sala de aula. Contudo, a dinâmica estabelecida pelo professor, em classe, foi a de que cada pessoa teria apenas uma chance de falar e só teria a palavra novamente se novas pessoas não se manifestassem.

Outra nuance do modelo hegemônico latente na participação dos rapazes, nessa plenária, foi a disputa pela posse do "conhecimento científico", simulado na atividade de investigação. George, Gabriel, César e Alessandro 
buscavam dominar o conhecimento, ao invés de construí-lo coletivamente. George e Gabriel expuseram enfaticamente seus argumentos em favor do movimento das estrelas, contradizendo as evidências apresentadas por Berta. Eles falaram com segurança, num tom de voz sutilmente intimidador. Isso reforçou a ideia de movimento das estrelas em outros grupos, apesar de as evidências apresentadas por Berta terem sido referendadas pelo professor. Alessandro e César também desconsideraram as observações da colega.

Após a plenária, a relação hegemônica de posse do conhecimento científico produzido no coletivo da turma ainda se fazia presente no grupo B. George, Gabriel e Charles descobriram que uma estrela variava de tamanho, expressaram sua satisfação, por meio de gestos e cumprimentos, e cuidaram para não alertar outros grupos, enquanto chamavam pelo professor. Já no grupo D, Berta descobriu a mudança de tamanho de uma estrela, se animou com a descoberta, confrontou as evidências com as colegas, anunciou-a em voz alta e quis dividi-la com o professor e com outro grupo.

A seguir apresenta-se a descrição da segunda e terceira aulas e, posteriormente, a análise dessas aulas. A descoberta do fenômeno é anunciada e uma nova relação com o "conhecimento científico" e com as tarefas em sala se estabelece.

\section{Segunda e terceira aulas}

$\mathrm{Na}$ aula seguinte, antes de distribuir as fotografias aos grupos, o professor lembra do referencial temporal (datas nas fotografias) e do espacial (Mickey), orienta os alunos a buscar mudanças, a partir da observação do que não está mudando, e anuncia que o jogo vai continuar: todos devem dar sua contribuição para a humanidade, como cientistas. Ele relembra o desafio do final da aula anterior, em que os alunos deveriam encontrar algum fenômeno só olhando as fotografias. Conta que pelo menos uma pessoa, um grupo, descobriu e fez uma manifestação de um grande prazer. Solicita que a pessoa se identifique, se quiser. Os alunos entreolham-se em silêncio e o professor esclarece:

- Professor: Alguém, no meio da aula, queria contar que tinha feito uma descoberta. Chegando a dizer "Eureka, venci o desafio!". 
Os alunos continuam olhando uns para os outros, aguardando que a pessoa se revele. Diante da indefinição dos alunos, o professor diz que o prazer foi no dia anterior e que não deve estar mais tão intenso, não dando qualquer pista de quem seja. Nesse momento, George ensaia a iniciativa de dizer alguma coisa, mas Berta, ao mesmo tempo, levanta o braço e diz:

- Berta: Fui eu... (meio sem jeito)

- Professor: Fale, Berta!

- Berta: Mas... eu não sei se está certo...

Os colegas fazem um pequeno gracejo com a manha de Berta e ela conta que, quando colocaram uma foto sobre outra, sobrepondo o "Mickey", perceberam que algumas estrelas estavam maiores e outras estavam menores. Imediatamente George leva as mãos ao rosto e dá um tapa na mesa. Gabriel encurva-se sobre a carteira, escondendo o rosto, e ambos gesticulam, em sinal de lamento, como se tivessem perdido um grande prêmio.

- George: Ai! Que ódio, "vér"! (coloca uma mão sobre a testa e tamborila na carteira com a outra).

O professor chama a atenção da turma para a reação do grupo e diz que aquela dor é o outro lado do prazer.

- George: Professor! A gente tinha falado isso, professor! No final da aula (agitando as mãos, visivelmente inconformado).

- Berta: Eu também.

O professor diz que Ihes deu a chance, mas que eles não quiseram se identificar. Dito isso, o professor dá continuidade à atividade. George e Gabriel "reclamam" com Berta por ela ter falado primeiro; ela retruca que eles tiveram a oportunidade de falar e não aproveitaram. Nos demais grupos, os alunos comentam entre si a descoberta do fenômeno. Irene diz que também ia falar, pois já havia percebido. José diz o mesmo. Matilde comenta que viram no final da aula, mas não deu tempo de contar ao professor. Michael relata a seu grupo que também percebeu, mas para ele o fenômeno era o fato de as estrelas não mudarem de posição.

Na seqüência, o professor restabelece a competição e alerta que os alunos ainda devem responder quais são as estrelas que mudam de tamanho. 
O prêmio para os descobridores será batizar a estrela com o nome do grupo. Embora a atividade tenha como um dos objetivos a compreensão do fenômeno, eles devem antes identificar as estrelas que serão estudadas. As fotografias são novamente distribuídas nos grupos, que, prontamente, começam a trabalhar.

Dessa vez, os grupos trabalham de maneira bastante uniforme: distribuem as fotografias entre si e começam a examiná-las procurando identificar as estrelas que mudam de tamanho. Em instantes, George chama o professor e mostra uma estrela que muda. O professor convoca todos os grupos, conta que eles deverão mostrar quais são as estrelas sem aponta-las, sem por o dedo, e entrega a cada um deles uma grade quadriculada de plástico transparente.

No grupo B, George, Gabriel e Charles trabalham de forma integrada: observam as fotografias e fazem comentários entre si, para verificar se as estrelas identificadas realmente mudam de tamanho. No grupo C, Jean coloca as fotografias em ordem e, em seguida, começam a procurar pelas estrelas. $O$ grupo $D$ organiza-se desde o início: procuram pelas estrelas que haviam visto no dia anterior e, posteriormente, decidem verificar se há estrelas que só aumentam ou que só diminuem.

No grupo $\mathrm{H}$, enquanto Tales coloca as fotografias em ordem, Roger mexe com colegas de outros grupos. Ele está em seu lugar e chama os colegas de outros grupos (Willian, James, Gabriel), dizendo: "Eu descobri!". Quando os colegas se viram para ele, o vêem cobrindo as fotografias com o envelope.

- Roger: Cobri! (coloca o envelope sobre as fotografias). Descobri! (retira o envelope).

Os colegas olham, riem e voltam ao trabalho. Tales termina de ordenar as fotografias e passa a examiná-los contra a luz. Roger toma duas delas em suas mãos e as examina do mesmo modo; coloca um das fotografias sobre a mesa e pega outra, e repete o procedimento. Nicolau está um pouco disperso e apenas observa o colega. Em cerca de quatro minutos, Roger joga as fotografias sobre a mesa e diz ter a explicação para o fenômeno. Nicolau fica atento ao colega. Para Roger, o fenômeno se deve ao movimento de translação, pois as estrelas diminuem. Nicolau concorda e Roger continua sua 
teoria e diz que a evidência é que as estrelas grandes quase não diminuem e as estrelas pequenas diminuem só um pouco. Nicolau pede que o colega conte ao professor, mas ele diz que não vai falar.

- Roger: Descobrimos, mas não vamos falar.

Roger chama os colegas de outros grupos (José, Julios) e diz para desistirem, pois eles já descobriram. Quando os colegas olham, ele faz a brincadeira: com o envelope, novamente, "cobre" e "descobre" as fotografias. Nicolau insiste que ele fale ao professor, mas ouve mais uma recusa. Assim que o professor passa próximo ao grupo. Nicolau o chama e diz que já descobriram. Roger conta que todas as estrelas "pequenininhas" se alteram. Antes que ele continue, o professor pergunta:

- Professor: Quais?

Nicolau diz que essa tarefa é mais difícil. Contudo, o professor determina que primeiro deixem claro quais são as estrelas que mudam de tamanho, e retira-se. Roger reclama:

- Roger: Aaah! (largando, imediatamente, a foto que segurava sobre a mesa).

Nicolau sugere que peguem um lápis para marcar as estrelas. No grupo $C$, James critica a atitude dos colegas por estarem querendo escrever no material que não pertence a eles. Enquanto Tales ainda estuda as fotografias, Roger e Nicolau se dispersam.

$$
\text { (...) }
$$

\section{Análise da segunda e terceira aulas}

O professor retomou a investigação em plenária solicitando que os grupos relembrassem os momentos finais da aula anterior.

O modelo hegemônico de competição, poder e domínio do conhecimento se revelou na reação de George e Gabriel diante da declaração de Berta. A relação desse grupo com as tarefas da sala de aula e a expectativa de obter status frente aos outros grupos sugere o que Connell (1995) definiu como "homens de razão" [tradução nossa]. Esse termo denomina um grupo de meninos e rapazes orientados por um modelo hegemônico de conhecimento e racionalidade, com a expectativa de obter as 
alavancas do poder econômico e social pela aquisição do conhecimento através da instituição escolar. Desde o final da primeira aula, destacou-se a maneira contrastante como Berta, no grupo D, e George e Gabriel, no grupo $B$, reagiram à descoberta do fenômeno. George e Gabriel guardaram a descoberta em seu grupo, esperando o "grande momento" para revela-la. Eles deixaram a chance passar, expressando grande frustração; ainda tentaram reivindicar a autoria ao professor, mas já era tarde.

A plenária permitiu a socialização das estratégias de investigação e das descobertas, deixando todos os grupos novamente em um mesmo nível, com a realização de uma tarefa que estava ao alcance de todos. Os grupos passaram a se organizar de maneira mais colaborativa, dividindo tarefas e confrontando evidências a partir das intervenções do professor.

A exceção a esse quadro de uniformidade no trabalho dos grupos e engajamento na investigação ocorreu no grupo $\mathrm{H}$, onde a relação de Roger com seus colegas evidenciava dois padrões de masculinidade. O primeiro era o hegemônico de conhecimento e racionalidade, que levou Roger a auxiliar o grupo apenas nas questões que exigiam "trabalho intelectual", recusando-se a fazer medidas ou anotações. Entretanto, Roger não respeitou as opiniões de seus colegas e seu desejo explícito de se engajarem na investigação, como vinham fazendo os outros grupos. Isso comprometeu seu desempenho na investigação e deixou o grupo em desvantagem em relação aos demais. $O$ segundo modelo de masculinidade aproxima-se do que Connell $(1995,2000)$ identifica como "masculinidade de protesto", vinculada a uma "cumplicidade" entre Roger e Nicolau (Connell, 1995). A "masculinidade de protesto" é uma maneira de adquirir prestígio entre os pares, marcar diferenças e obter prazer pelo confronto às regras e pelo desafio à autoridade. Nicolau não possuía outras fontes para o sucesso acadêmico naquela escola; isso o tornava susceptível a recorrer à "masculinidade de protesto", como meio de obter prestígio entre os colegas. Ele quis se engajar com a atividade em diversos momentos, mas a influência de Roger o demoveu. Havia entre os dois uma cumplicidade quanto aos gracejos e brincadeiras em classe. Nesse caso, destaca-se a tendência de Roger em desafiar as regras na sala de aula e dissuadir seu grupo e os outros grupos de se concentrarem na tarefa. Mesmo quando se mostrou curioso ou intrigado com o fenômeno, Roger agiu como se fosse intocável. 


\section{Considerações finais}

Cada sociedade constrói suas próprias representações de gênero, de escola e de disciplinas escolares de prestígio. Com o tempo, certa sociedade pode se ver refém de estereótipos que criou. No que se refere à educação de meninos e meninas, esses estereótipos podem minar o esforço de educá-los na sua diversidade. Trabalhou-se aqui com base no conceito de masculinidade de Connell (1995), pois permite interpretar interações entre rapazes, percebendo sua relação com um padrão hegemônico de masculinidade. Tomar o conceito de masculinidade hegemônica como referência permite a identificação de outras masculinidades; contudo, não se deve caracterizá-las, já que as tipologias são inadequadas para representar traço tão fluído e dinâmico como a masculinidade (Swain, 2006).

Neste trabalho, observaram-se rapazes durante uma atividade escolar que desafia alunos e alunas, ao instigá-los a investigar um fenômeno natural. Constatou-se a predisposição dos rapazes para o desafio e para competição, uma vez que tinham a possibilidade de fazer uma "descoberta científica". Notou-se, contudo, que essa disposição se manifesta com diferentes matizes em diferentes configurações de masculinidade. Por exemplo: nos eventos em que se configurou o modelo hegemônico de masculinidade, os rapazes apresentaram disposições voltadas para o conflito, dominação e disputas de poder, o que prejudicou tanto o progresso do grupo, quanto a aprendizagem de seus membros. Essa configuração de masculinidade predominou entre alguns rapazes e se desenrolou nos grupos de diversas maneiras. Houve também configurações de masculinidades em que o desafio e a competição com outros grupos guiaram o planejamento e a organização de tarefas. Nesses casos, o trabalho colaborativo foi predominante e os alunos conseguiram articular a curiosidade pelo fenômeno com tarefas que os levassem à "descoberta científica".

Os resultados aqui obtidos chamam a atenção por revelarem nuances do modelo de masculinidade hegemônica ocidental que inibem a relação colaborativa, a valorização da diversidade e o respeito mútuo. O conceito de masculinidade permitiu perceber que essas nuances estavam latentes nas diversas relações estabelecidas em aula. A dificuldade para identifica-las indica o risco delas passarem desapercebidas ou serem naturalizadas, dentro da instituição escolar. Por outro lado, também se pôde observar que professor 
e situação de aprendizagem podem minimizar os efeitos daquelas nuances e direcionar as masculinidades em prol da colaboração e do desenvolvimento de alunos e alunas.

Cabe ressaltar uma imbricação particular entre o padrão hegemônico de masculinidade e o aproveitamento escolar em Física no ensino médio. A Física é uma disciplina escolar de prestígio em que se pode recorrer a situações desafiadoras, como atividades abertas de investigação. Dimensões importantes da formação dos rapazes são colocadas em risco quando, numa disciplina como a Física, eles se orientam pelo padrão hegemônico de masculinidade ocidental - que legitima e valoriza, por exemplo, a competição, uma objetividade ultra-racional, o individualismo, a distância emocional, a dominação, etc. Ao associar tal padrão de masculinidade ao protótipo do cientista genial, os rapazes podem não enxergar a ciência como uma atividade humana pautada pelo debate, pela colaboração, por pequenas tarefas, procedimentos rotineiros e até repetitivos. Quando isso ocorre, o engajamento dos rapazes nessa disciplina pode ser genuíno; porém, em torno de aspectos que são insuficientes para garantir seu pleno desenvolvimento.

No contexto das aulas analisadas, houve evidências de que a emancipação dos rapazes da masculinidade hegemônica pode ocorrer em atividades escolares que criem oportunidades para que todos os alunos e alunas colaborem entre si em um mesmo nível. Esse tipo de atividade tem potencial para gerar conflitos e tensões em torno das predisposições hegemônicas. Esses conflitos surgem quando os alunos precisam negociar decisões e ações para a realização das tarefas. Tais situações podem alterar as configurações de masculinidade, transformando padrões de resistência entre colegas em relações de colaboração. Além disso, a dinâmica de atividades coletivas de caráter colaborativo permite que o professor valorize outros modelos de masculinidade. Essa pode ser uma maneira de fazer com que disputas de poder e relações de dominação cedam lugar a configurações e práticas de gênero que promovam o pleno desenvolvimento de alunos e alunas. 


\section{Referências}

Blakemore, J., \& Centers, R. (2005). Characteristics of boys' and girls' toys. Sex Roles, v. $53, n^{\circ} 9-10,619-633$.

Bourdieu, P. (1995). Dominação masculina. Educação e Realidade, v. 20, n² 2, 133-184.

Brito, R. (2006). Intrincada trama de masculinidades e feminilidades: Fracasso escolar e meninos. Cadernos de Pesquisa, v. 36, n 127, 129-149.

Carvalho, M. P. (2001). Mau aluno, boa aluna? Como as professoras avaliam meninos e meninas. Estudos Feministas, v. 9, $\mathrm{n}^{\circ}$ 2, 554-574.

Carvalho, M. P. (2003). Sucesso e fracasso escolar: Uma questão de gênero. Educação e Pesquisa, v. 29, $\mathrm{n}^{\circ}$ 1, 185-193.

Carvalho, M. P. (2004). Quem são os meninos que fracassam na escola? Cadernos de Pesquisa, v. 34, $\mathrm{n}^{\circ}$ 121, 185-193.

Chassot, A. (2003). A ciência é masculina? São Leopoldo, RS: UNISINOS.

Connell, R. W. (1995). Masculinities: Knowledge, power and social change. Berkeley, Los Angeles: University of California Press.

Connell, R. W. (1995). Políticas da masculinidade. Educação e Realidade, v. 2, n²0, 185-206.

Connell, R. W. (2000). The men and the boys. Berkeley: University of California Press.

Connell, R. W., \& Messerschmidt, J. W. (2005). Hegemonic masculinity: Rethinking the concept. Gender \& Society, v. 19, n 6, 829-859.

Cruz, T., \& Carvalho, M. P. (2006). Jogos de gênero: O recreio numa escola de ensino fundamental. Cadernos Pagu, s/v., n 26, 113-143.

Donini, E. (2001). A construção cultural das Ciências da Natureza. Gêneros, personagens e fatos históricos. Projeto POLITE - Saberes e Liberdade.

Giddens, A. (2005). Educação. In A. Giddens, Sociologia (pp. 394-424). Porto Alegre: Artmed.

Haenfler, R. (2004). Manhood in contradiction: The two faces of straight edge. Men and Masculinities, v. 7, $\mathrm{n}^{\circ}$ 1, 77-99.

Louro, G. L. (1992). Uma leitura da História da Educação sob a perspectiva de gênero. Teoria e Educação, s/v., $\mathrm{n}^{\circ}$ 6, 53-67.

Martino, W., \& Berrill, D. (2003). Boys, schooling and masculinities: Interrogating the "right" way to educate boys. Education Review, v. 55, n² 2, 99-117.

Martino, W., \& Meyenn, B. (2001). What about the boys? Issues of masculinity in schools. Buckingham - Philadelphia: Open University Press.

Rocha, C., \& Ferreira, M. (2002). Aprender a ser rapaz entre rapazes e raparigas. Masculinidades em duas escolas $\mathrm{C}+\mathrm{S}$ do distrito do Porto. Trabalhos de Antropologia e Etnologia, v. 42, $\mathrm{n}^{\circ}$ 1-2, 49-68.

Souza, E. (2006). Marcadores sociais da diferença e infância: Relações de poder no contexto escolar. Cadernos Pagu, s/v., n 26, 169-199.

Statham, J. (1986). Daughters and sons: Experiences of non-sexist childraising. Oxford: Basil Blackwell. 
Swain, J. (2006). Reflections on patterns of masculinity in school settings. Men and Masculinities, v. 8, $n^{\circ} 3,331-349$.

Taft, R. (1999). Ethnographic research methods. In J. Keeves \& G. Lakomski (Eds.), Issues in Educational Research (pp. 113-120). Oxford: Elservier Science.

Weaver-Hightower, M. (2003). The "boy turn" in research on gender and education. Review of Educational Research, v. 73, $n^{\circ} 4,471-498$. 


\title{
IMBRICATIONS BETWEEN PHYSICS LEARNING AND MASCULINITY IN AN EDUCATION IN CRISIS
}

\begin{abstract}
In a context of boys' education crisis, we aimed to characterize latent aspects of masculinity that bring out implications to individual and collective learning in Secondary School. The methodological design has an ethnographic inspiration: Physics classes of first year students were observed for an academic year in Brazil. A microanalysis of a thematic unit was conducted, focusing boys' main interactions. Three classes are presented in detail - video and audio recorded. Some masculinity manifestations were predominant between boys in classroom activities that were challenging, that were competitive and others, in which rules had to be observed. Results suggest the kind of circumstances in which such masculinities might be manifested, jeopardizing the development of classroom activities and learning groups' dynamics.
\end{abstract}

Keywords

Masculinity representations; Physics education; Investigation activities

\section{L'APPRENTISSAGE DE LA PHYSIQUE ET LA MASCULINITÉ RACCORDÉS DANS UNE ÉDUCATION EN CRISE}

\section{Résumé}

Dans le contexte de la dite crise de l'éducation masculine, nous avons tenté de caractériser les aspects latents de la masculinité ayant des implications pour l'apprentissage individuel et collectif dans l'enseignement secondaire. L'inspiration de la méthodologie est d'ordre ethnographique: des cours de Physique dans une classe de la première série de l'enseignement secondaire au Brésil (équivalent à la seconde au lycée) ont été accompagnés pendant 
une année. Une micro- analyse d'une unité thématique a été réalisée portant sur les interactions prédominantes entre les garçons. Trois cours, enregistrés et filmés sur vidéo, sont présentés en détail. Certaines manifestations de la masculinité ont prédominé parmi les jeunes gens en situation de défi, situation de compétition ou d'autres situations, encore dont les règles ont dû être observées. Les résultats indiquent dans quelles circonstances ces manifestations de la masculinité portent préjudice au développement des activités en salle de classe et au bon fonctionnement de l'ensemble du groupe d'apprenants.

Mots-clé

Représentations de la masculinité; Enseignement de la Physique; Activité investigatrice

Recebido em Abril, 2009 Aceite para publicação em Janeiro, 2011 Horizonte, Minas Gerais, Brasil. 